\title{
Bio-optical properties of gelbstoff in the Arabian Sea at the onset of the southwest monsoon
}

\author{
WiEBKe BREVES and RAINER REUter \\ Carl von Ossietzky Universität Oldenburg, Fachbereich Physik, D-26111 Oldenburg, Germany.
}

\begin{abstract}
As part of the German JGOFS Indian Ocean Programme, a cruise occurred in the Arabian Sea in May 1997 at the onset of the southwest monsoon. Data on gelbstoff, chlorophyll $a$ and tryptophan-like fluorescence as well as gelbstoff absorption were obtained. They indicate, that these optical parameters support the interpretation of hydrographic and biogeochemical conditions. Tryptophan-like fluorescence seems to be a useful indicator of changes in the constitution of the biomass.

A comparison of gelbstoff absorption and fluorescence data from the upper $100 \mathrm{~m}$ reveals only a weak covariance. Special emphasis is given to the fit procedure used for retrieving the exponential slope $S$ of the spectral absorption coefficient. $S$ values with a mean of $0.016 \mathrm{~nm}^{-1}$ are found in the 350 to $480 \mathrm{~nm}$ wavelength range. A mean slope $S$ set to the frequently reported value of $0.014 \mathrm{~nm}^{-1}$ in the exponential description of gelbstoff absorption might lead to a systematic over/underestimation, and thus to systematic errors, if single-wavelength absorption values are extrapolated to other spectral regions on the basis of this parameter.
\end{abstract}

\section{Introduction}

Fluorescence measurements have been utilised in oceanography since the early sixties to detect phytoplankton pigments and chromophoric constituents of dissolved organic matter (gelbstoff, yellow substance or gilvin) by their specific fluorescence (Kalle 1963; Yentsch and Menzel 1963; Lorenzen 1966; Chen and Bada 1992; Mopper and Schultz 1993; De Souza Sierra et al 1994; Kirk 1994; Coble 1996). Nowadays these measurements are widely used in water mass analysis as well as for phytoplankton biomass determinations. More recently a relation between UV fluorescence and aromatic amino acids bound to proteins, that is tryptophan and tyrosine, has been reported (Determann 1995; Determann et al 1998).

Gelbstoff, the light absorbing part of dissolved organic matter (DOM) in water, as well as tryptophan fluoresce when excited in the near ultraviolet. Due to its optical definition, gelbstoff 'concentration' is expressed by the absorption coefficient of filtered water at a given wavelength. The fluorescence emission of gelbstoff covers a wide spectral range at blue-green wavelengths. Its emission maximum is at 420 to $450 \mathrm{~nm}$, depending on its origin (de Souza Sierra et al 1991; Coble 1996). Besides its fluorescence, gelbstoff is known for its absorption characteristics, which are important in the context of remote sensing and radiative transfer in the water column. Several attempts have been made to relate fluorescence which is measurable more rapidly and with higher sensitivity to absorption (Green and Blough 1994; Ferrari and Tassan 1991). When viewed over a broad range of concentrations including also coastal waters with higher DOM loads such relations seem to hold within reasonable accuracy. The open ocean, however, is characterised by low DOM concentrations. Thus, the relation of absorption to fluorescence in this region is of particular interest. Tryptophan, an aromatic acid, depicts its maximum fluorescence in the near UV at about $340 \mathrm{~nm}$ when excited in the UV region. Proteins bound to cells or their dissolved derivates cause this fluorescence signal. The fluorescence of

Keywords. Gelbstoff; chlorophyll; absorption; fluorescence; tryptophan-like. 


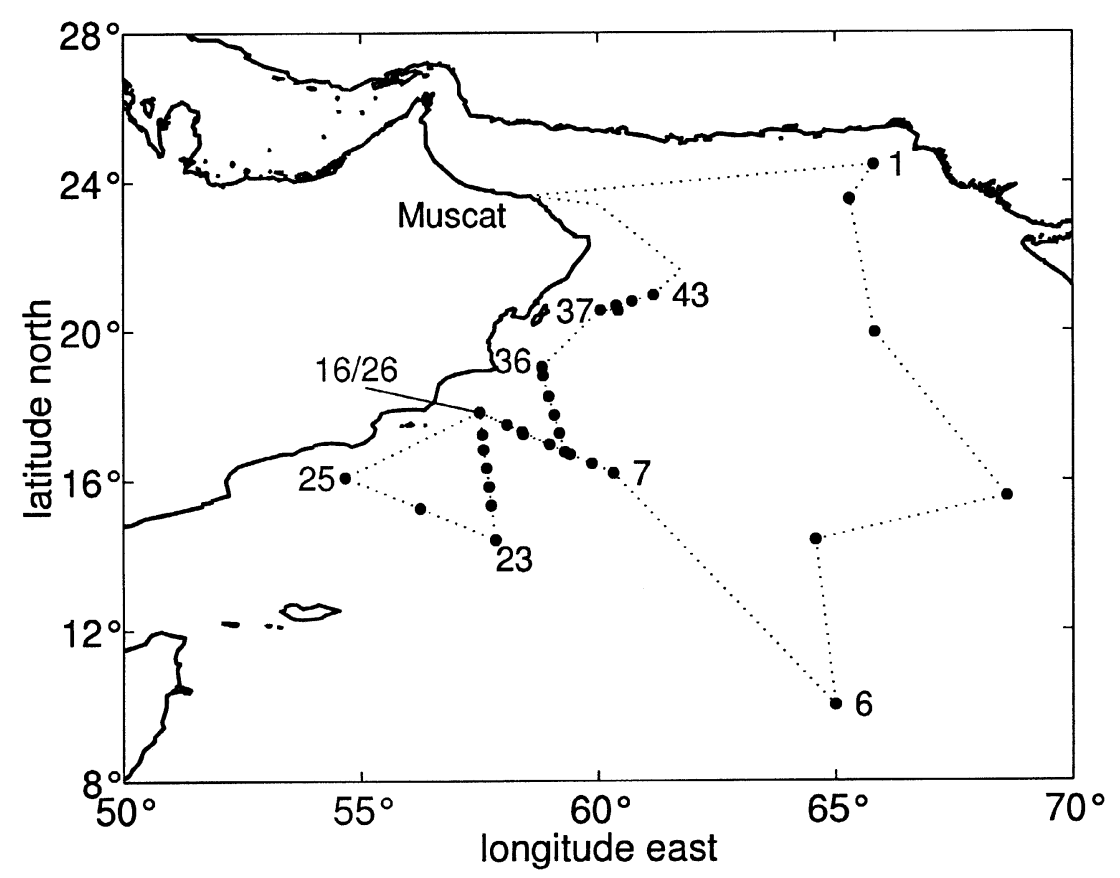

Figure 1. Cruise track and position of depth stations of the cruise So119 of R.V. Sonne in the Arabian Sea, 12th May to 10th June 1997.

free and bound tryptophan is affected by a number of factors. It is quite heterogeneous, since the location of its fluorescence band and the quantum efficiency differ due to the micro-environment (Wolfbeis 1985). The occurrence of such signals was first reported by Traganza (1969), and attributed to aromatic amino acids or their metabolites by Ewald et al (1986). They originate from proteins in dissolved organic matter released by recent biological activity (Mopper and Schultz 1993; De Souza Sierra et al 1994), but also from phytoplankton (Baek et al 1988) and bacteria (Daltiero et al 1986; Determann et al 1998). Their relevance for a better understanding of microbiological processes is not yet fully understood.

Phytoplankton chlorophyll $a$ and phaeopigments fluoresce at $680 \mathrm{~nm}$ when excited at visible wavelengths. These signals are typically found in the upper water column due to the presence of phytoplankton biomass.

The JGOFS cruise So119 of R.V. Sonne took place from 12th May to 10th June 1997 during the onset of the southwest monsoon (figure 1). The positions of depth stations were selected in the oligotrophic central Arabian Sea as well as in the upwelling region near the Omani coast. The paper aims at the presentation of fluorescence and absorption data measured in these regions. Relationships between these parameters are examined at low concentration levels and with respect to other hydrographic data, and their potential use in oceanography is discussed.

\section{Methods}

\subsection{Sampling}

Water samples were taken using a rosette with 24 ten litre Niskin bottles assembled to a Seabird 911+ CTD probe. Sampling was mostly done at depths corresponding to 5-35-50-80-120-150-200-300-450-600-8001000-1250-1500-2000-2500-3000-3500 and 4000 meter. The samples collected for in vitro fluorescence and absorbance measurements were filled in amber $500 \mathrm{ml}$ glass bottles and stored in isolating boxes to keep the samples at their in situ temperature. Optical measurements were mostly done immediately after sampling and completed about $3 \mathrm{~h}$ later.

\subsection{In vitro fluorescence measurements}

Fluorescence measurements of the collected water samples were done with a Perkin Elmer model LS50 luminescence spectrometer. To minimise a possible contamination of the samples and the cuvette a fused silica flow-through cuvette was used. Excitation wavelengths of 341 and $420 \mathrm{~nm}$ were used for gelbstoff and chlorophyll detection. Emission intensities were read at $430 \mathrm{~nm}$ and $680 \mathrm{~nm}$. The $341 \mathrm{~nm}$ excitation was chosen due to the occurrence of high straylight levels from the excitation monochromator during that campaign. These were caused by a severely oxidised surface of the grating in the excitation monochromator. Excitation at UV wavelengths was therefore not feasible since the spectra were obscured by false light. 
To overcome this problem a $341 \mathrm{~nm}$ interference filter was used in the excitation light path, thus enabling emission spectra with $341 \mathrm{~nm}$ excitation that were not degraded by false light.

This problem was less severe with $420 \mathrm{~nm}$ excitation used for chlorophyll fluorescence measurements. False light levels were smaller at VIS excitation wavelengths and did not hamper the intensity reading of the $680 \mathrm{~nm}$ chlorophyll emission band. To reconstruct the entire emission spectrum the false light contributions were eliminated by subtraction of blank spectra taken with purified water during the cruise. These blank spectra are considered to show the same straylight levels but negligible fluorescence. Their subtraction thus leads to 'cleaned' emission spectra.

A spectral calibration in the 380 to $630 \mathrm{~nm}$ range of the emission side of the instrument was done before the cruise with quinine sulfate dihydrate in $0.1 \mathrm{~mol} \mathrm{l}^{-1}$ HClO4 (Velapoldi and Mielenz 1980) The spectral range from 250 to $380 \mathrm{~nm}$ was corrected by a wavelength-synchronous excitation/emission scan with a diffuse reflector (Spectralon) at the position of the sample cuvette. A calibrated tungsten lamp (OSRAM Wi9) with $2856 \mathrm{~K}$ brightness temperature was used for the calibration of the red part of the spectrum from 630 to $750 \mathrm{~nm}$. A control of this spectral correction could not be done during the cruise, following the degradation of the grating in the excitation monochromator. Despite this uncertainty and with the attempt to derive quantitative spectra, fluorescence readings were normalised to the integrated emission band of water Raman scattering, from which Raman units were derived (Determann et al 1994). The relative error of this calibration is estimated to be $5 \%$.

\subsection{In vitro absorption coefficient measurements}

Measurements of the spectral absorption coefficient were carried out from 200 to $800 \mathrm{~nm}$ wavelength with a Perkin Elmer Lambda 18 spectrophotometer. Two fused silica cuvettes of $10 \mathrm{~cm}$ pathlength were used in the sample and the reference light path of the instrument. Each sample was measured in untreated form and after filtration on a Schleicher \& Schüll GF 50 glassfiber filter with $0.45 \mu \mathrm{m}$ pore size against purified water in the reference cuvette. To avoid sample degradation from organic impurities in the filter material, the filters were pre-combusted at $450^{\circ} \mathrm{C}$ for $5 \mathrm{~h}$.

The resolution of the readings is $0.002 \mathrm{~m}^{-1}$. Because of an instrumental long-term drift of about $\Delta a=0.03$ $\mathrm{m}^{-1} \mathrm{~h}^{-1}$ an offset correction was necessary. Assuming the absorption due to gelbstoff to be negligible in the region between 600 and $700 \mathrm{~nm}$ in oceanic waters, the offset is calculated as the mean of the data within this wavelength range. The fit does not account for any further correction for scattering by residual particles in the filtered samples. However, the contribution of scattering particles passing a $0.45 \mu \mathrm{m}$ filter to the measured absorption spectrum is small in oceanic waters (Bricaud et al 1981) and was not considered further.

\subsection{In situ fluorescence measurements}

During So119, a bio-optical sensor package was used, which includes a fluorometer with several excitation and emission wavelengths (Heuermann et al 1995), a CTD probe (model OTS 3000, ME Meerestechnik Elektronik, Germany) with a Clark type oxygen sensor, and a central unit for bi-directional data transmission (Barth et al. 1997). The maximum operating depth of the sensor package is $3000 \mathrm{~m}$.

Within the fluorometer, three excitation wavelengths can be set to spectral regions, where the fluorescence efficiency of substances under investigation is high. During So119 they were set to $270 \mathrm{~nm}$ for a specific excitation of gelbstoff and tryptophan, and to $420 \mathrm{~nm}$ for excitation of the phytoplankton pigment chlorophyll $a$. The detection assembly of the instrument consists of a modular set-up of ten identical modules with selectable wavelengths. Interference filters with $10 \mathrm{~nm}$ bandwidth on the excitation and the emission side of the water Raman scatter detection channels allow for a specific measurement of this signal. It is used for normalising the gelbstoff, tryptophan, and chlorophyll fluorescence readings. The bandwidth of interference filters used for gelbstoff and chlorophyll measurements is $20 \mathrm{~nm}$ to increase the sensitivity of these detection channels. In summary, excitation and emission wavelength combinations used during the cruise for in situ measurements were in the visible domain $420 / 680 \mathrm{~nm}$ for the detection of chlorophyll fluorescence and 420/ $490 \mathrm{~nm}$ for water Raman scattering. In the UV, wavelength pairs of $270 / 450 \mathrm{~nm}$ for gelbstoff fluorescence, $270 / 350 \mathrm{~nm}$ for tryptohan-like fluorescence and $270 / 300 \mathrm{~nm}$ for the measurement of water Raman scattering were chosen.

The spectral sensitivity of the fluorescence readings was calibrated on board the ship with a commercial humic acid (Aldrich H 1,675-2) dissolved in purified water in different dilution steps. Subsamples were measured with the Perkin Elmer LS50 luminescence spectrometer using the same excitation and emission wavelengths. In contrast to the UV and blue/green spectral range its fluorescence emission is insufficient in the red for the purpose of sensitivity calibration. The quality of the dilution series in the red part of the spectra taken with the LS50 is not satisfying for calibration. Therefore, the in situ (ex420/em680) measurements are given in relative units. Since water samples were not analysed for their tryptophan fluorescence, the in situ (ex270/em350) data can also be given in relative units only. 


\section{Results and Discussion}

\subsection{Absorption and fluorescence of gelbstoff}

The absorption coefficient of gelbstoff $a_{g}$ is usually described via an exponential law:

$$
a_{g}(\lambda)=a_{g}\left(\lambda_{0}\right) \exp \left(-S\left(\lambda-\lambda_{0}\right)\right)
$$

where $\lambda$ is the wavelength, $a_{g}(\lambda), a_{g}\left(\lambda_{0}\right)$ are the absorption coefficients at wavelength $\lambda$ and reference wavelength $\lambda_{0}$. This relation was found to be valid at wavelengths ranging from about 350 to $650 \mathrm{~nm}$ (Jerlov 1976; Bricaud et al 1981; Zepp and Schlotzhauer 1981; Hojerslev 1988; Kirk 1994) with the 'mean exponential slope' $S$ taking on a value of $0.014 \mathrm{~nm}^{-1}$ with a standard deviation of $0.0032 \mathrm{~nm}^{-1}$ in a variety of waters (Bricaud et al 1981).
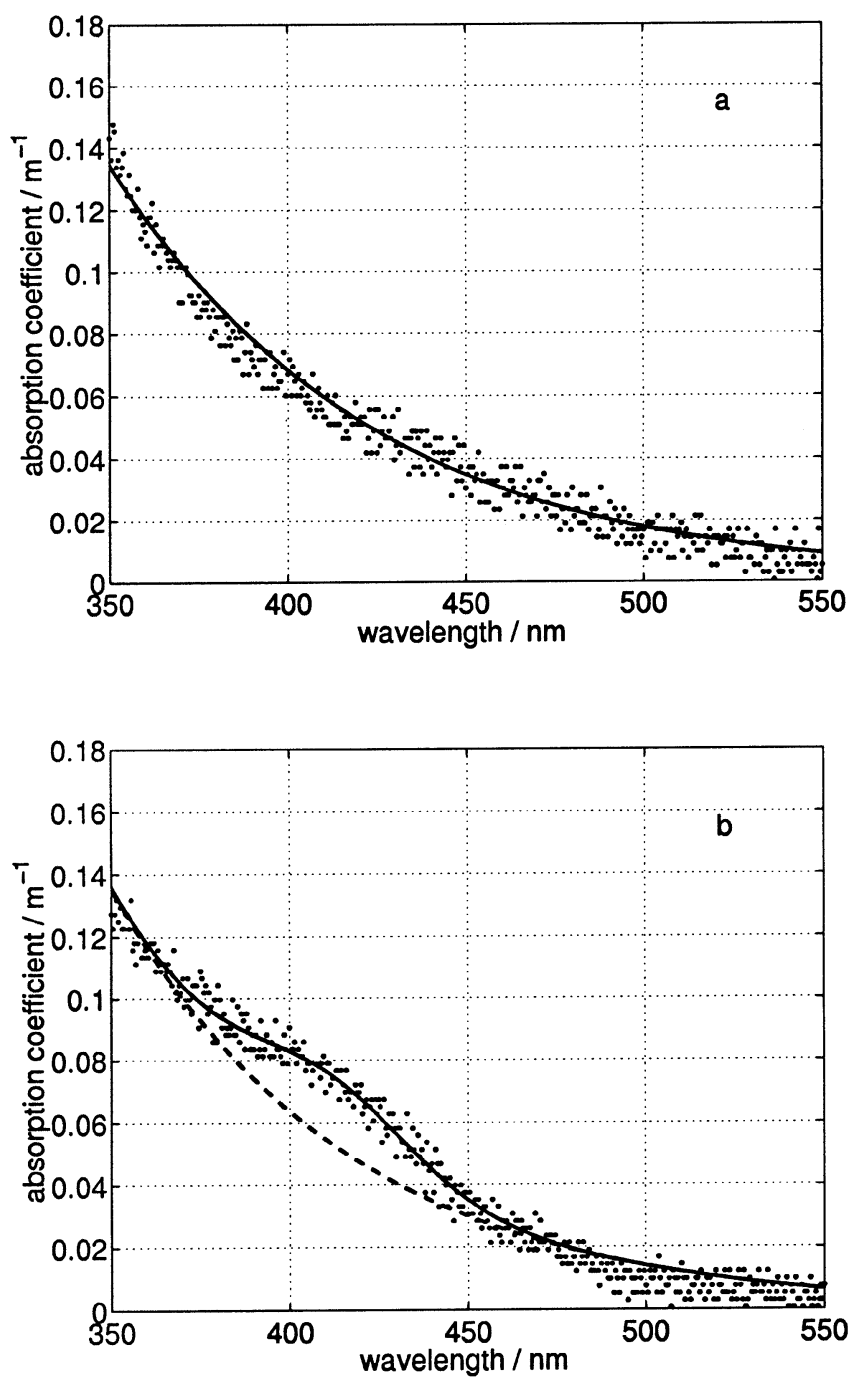

Figure 2. Example of absorption spectra from station 12, 26th May $97,17^{\circ} 14.4^{\prime} \mathrm{N}, 58^{\circ} 31.3^{\prime} \mathrm{E}$. a) sample from $50 \mathrm{~m}$, b) sample from $600 \mathrm{~m}$. Dots represent data points, the solid lines, the fit on two wavelength intervals (350-370 nm and 450-480 nm), accounting for the additional absorption band (roughly between 370 and $450 \mathrm{~nm}$ ).
The spectra measured on samples during So119 show the same exponential decrease versus increasing wavelength (figure 2a). However, an additional absorption band is observed in the spectra from samples taken in the oxygen minimum zone, which leads to a deviation from the 'typical' exponential appearance (figure 2b). This band remains unchanged when filtering the samples with $0.45 \mu \mathrm{m}$ glass fibre filters. It is therefore attributed to dissolved material, or to particles of much less than a micrometer in size. It correlates closely with the emission of fluorescence in the 650 to $680 \mathrm{~nm}$ range (Breves et al unpubl.).

For further analysis, a least-square-fit was calculated to determine the individual slope $S$ of each spectrum, taking into account the data from 350 to $370 \mathrm{~nm}$ and from 450 to $480 \mathrm{~nm}$ only. This division of the regression interval is necessary because of the absorption band centred at about $412 \mathrm{~nm}$. Its disregard may result in a faulty fit, that is in misleading parameters $S$ and $a_{g}(\lambda)$, as can be seen in figure 2 .

The fit of the So119 data calculated from a total of 267 spectra yields $S$ values from 0.012 to $0.024 \mathrm{~nm}^{-1}$ with a mean of $0.0162 \mathrm{~nm}^{-1}$. The standard deviation of $S$ is $0.002 \mathrm{~nm}^{-1}$. Spectral characteristics are variable with depth, but show irregular pattern. Pooling the data from all depths could lead to a bias if the slope parameter $S$ is used to extrapolate absorption coefficients in the euphotic zone. Thus, spectra were grouped into data from the euphotic zone and from below. The depth of the euphotic zone was in the interval of approx. 50 to $100 \mathrm{~m}$ and roughly coincides with the depth of the deep chlorophyll maximum (Breves et al unpubl.). Therefore, the upper $100 \mathrm{~m}$ are referred to as euphotic zone. The analysis with grouped data from the euphotic zone and from below (mainly from the oxygen minimum zone OMZ) yields mean $S$ values of $0.0154 \mathrm{~nm}^{-1}$ and of $0.0165 \mathrm{~nm}^{-1}$, respectively. These $S$ values are slightly higher than the above mentioned mean exponential slope value. Values of the absorption coefficient $a_{g}(375)$ lie in the range of 0.02 and $0.33 \mathrm{~m}^{-1}$, which is typical for oceanic areas. The absorption coefficients coincide with the category of open ocean conditions defined by Bricaud et al. (1981) of $a_{g}(375)$ between 0.06 and $0.3 \mathrm{~m}^{-1}$. Since our data at $375 \mathrm{~nm}$ might be influenced by the trailing edge of the additional absorption band (figure 2), values of the absorption coefficient $a_{g}(350)$ are chosen for further analysis. They lie in the range of 0.03 to $0.47 \mathrm{~m}^{-1}$, and between 0.09 and $0.21 \mathrm{~m}^{-1}$ below the euphotic zone.

The $a_{g}(350)$ data are used to calculate values of $a_{g}(440)$ with equation (1) and are compared with the measured coefficients. The wavelength of $440 \mathrm{~nm}$ is chosen because it is of great importance in remote sensing of chlorophyll. In a first approach, this is done by setting $S=0.014 \mathrm{~nm}^{-1}$. In the second, the same calculation is done with $S=0.016 \mathrm{~nm}^{-1}$, that is the mean slope of the So119 data set. Finally, it is done 
with the individually calculated $S$ values. The results are misleading since the measured coefficient at $440 \mathrm{~nm}$ is still influenced by the trailing edge of the additional absorption band (figure 2). The basis for an extrapolation is the exponential law, but at $440 \mathrm{~nm}$ this law cannot be applied. Thus the comparison is not feasible. To overcome this problem, the same procedure is carried out for $a_{g}(470)$, where the additional absorption band is almost negligible. The comparison of extrapolated and measured values yields mean relative errors of $35 \% \quad\left(S=0.014 \mathrm{~nm}^{-1}\right), 6 \%$ $\left(S=0.016 \mathrm{~nm}^{-1}\right)$ and $0.3 \%$ (individually calculated $S$ values).

Since values of $a_{g}(470)$ estimated on the basis of individually calculated $S$ values are good (figure 3a), it is assumed that the 'true' value of the exponential characteristic can be described via this fit in the wavelength domain of $350-480 \mathrm{~nm}$. The calculated values of $a_{g}(440)$ are now compared to these values (figure $3 \mathrm{~b}, 3 \mathrm{c}$ ). The mean errors are reduced to $25 \%$ using $S=0.014 \mathrm{~nm}^{-1}$ and to $4 \%$ using $S=0.016 \mathrm{~nm}^{-1}$. With the assumption of a fixed mean $S=0.014 \mathrm{~nm}^{-1}$, Bricaud et al. (1981) deduce a potential error of $\pm 25 \%$, if gelbstoff absorption coefficients at $440 \mathrm{~nm}$ are derived using equation (1) from a measurement at a single wavelength. Our absorption coefficients derived with this $S$ value lie within this range, but are systematically shifted to positive deviations. Using the more 'adequate' mean $S$ leads to reduced and more evenly distributed errors. The absorption coefficients at $440 \mathrm{~nm}$ extrapolated from $350 \mathrm{~nm}$ with and without accountance for the additional Gauss characteristic are compared in figure 3(d). A fixed $S$ value of $0.014 \mathrm{~nm}^{-1}$ would mostly result in a systematic overestimation of the absorption coefficient. Disregarding the additional absorption
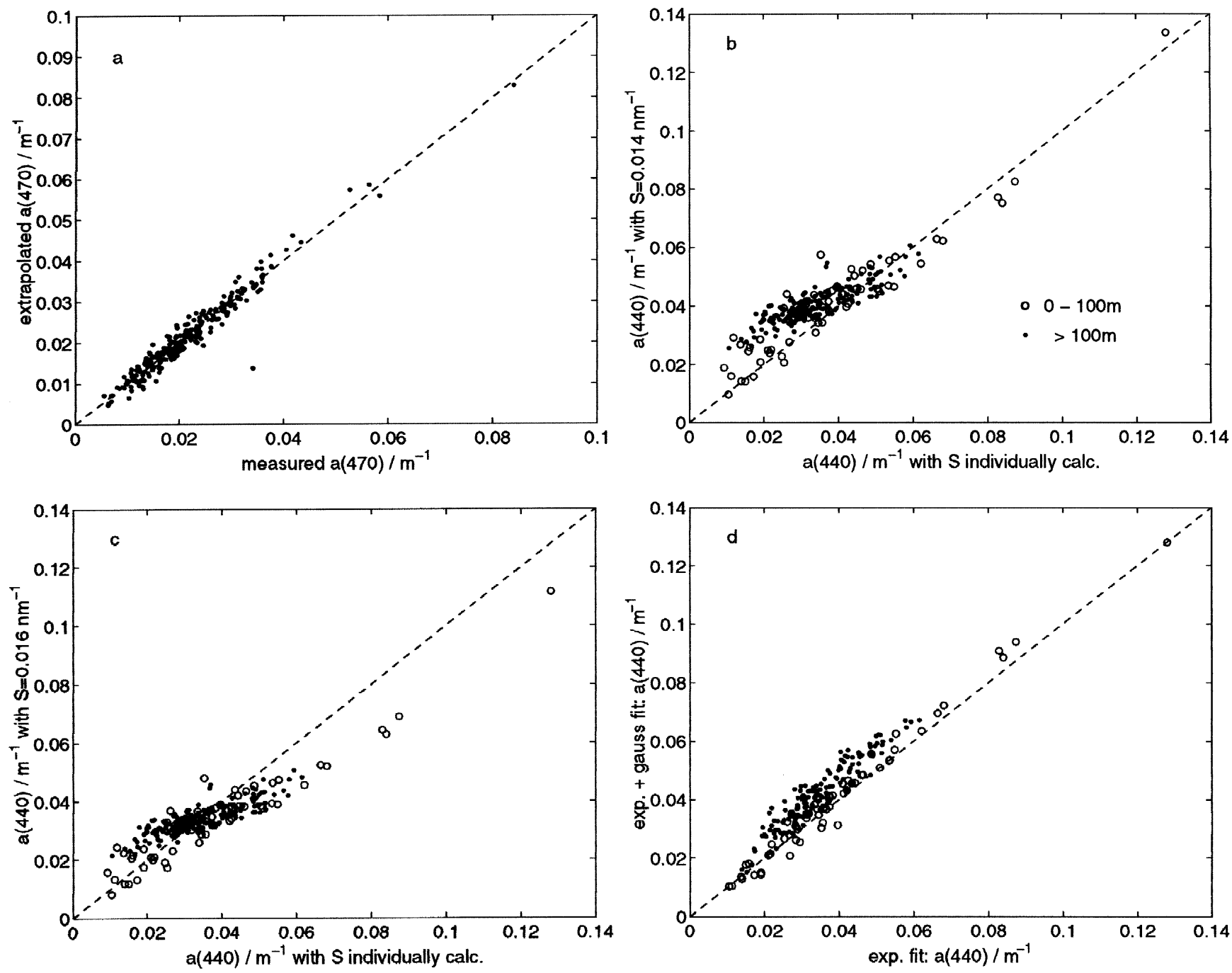

Figure 3. Comparison of measured and calculated absorption coefficients using different $S$ values. a) measured $a_{g}(470)$ vs. $a_{g}(470)$ extrapolated with individually calculated $\mathrm{S}$ values, b) $a_{g}(440)$ extrapolated with $S=0.014 \mathrm{~nm}^{-1}$ vs. $a_{g}(440)$ extrapolated with individually calculated $S$ values, c) $a_{g}(440)$ extrapolated with $S=0.016 \mathrm{~nm}^{-1}$ vs. $a_{g}(440)$ extrapolated with individually calculated $S$ values, d) absorption coefficients at $440 \mathrm{~nm}$ extrapolated from $350 \mathrm{~nm}$ using the individually calculated $S$ values, but disregarding the additional absorption band versus $a_{g}(440)$ accounting for this feature. 
band leads to underestimation. However, the quality of these extrapolations depends on accurately determining $S$ in the presence of deviations from the exponential law. Leading or trailing edges of other absorption bands might influence the $S$ fitting. The distinction of data from the OMZ and the euphotic zone reveals that the additional absorption band is predominately important at depth of the OMZ, while the changes in the spectral property $S$ also influence inherent optical properties of the euphotic zone.

Functional relationships of the absorption coefficient to the fluorescence emission are of particular interest. They depend on the molecular composition of gelbstoff, and can therefore give information on its origin and state within the organic carbon cycle. In figure 4 profiles from station 7 are given as an example. At $50 \mathrm{~m}$ depth, which is also the depth of the chlorophyll maximum, gelbstoff absorption was highest when compared with the other stations. Gelbstoff fluorescence shows a less pronounced local maximum at the same depth. This structure of the profile at $50 \mathrm{~m}$ depth is probably due to in situ production of gelbstoff by phytoplankton and/or its degradation products (Spitzy and Ittekkot 1986), that are characterised by lower fluorescence efficiency than the pool of old refractory dissolved organic matter (Determann 1995). Local maxima of the absorption coefficient at $350 \mathrm{~nm}$ at the depth of the chlorophyll maximum are visible at several stations, but no quantitative correlation is evident.

A comparison of the gelbstoff absorption at $350 \mathrm{~nm}$ and fluorescence $F(341 / 430)$ for the upper $100 \mathrm{~m}$ as well as for data from all depths is shown in figure 5 . It also shows a slight trend of a negative correlation
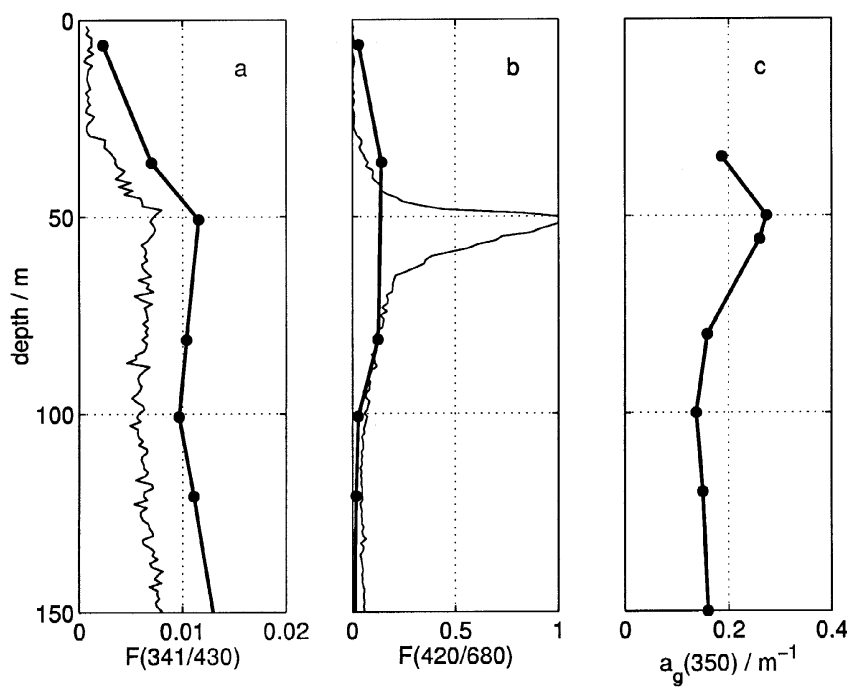

Figure 4. Vertical profiles of gelbstoff and chlorophyll $a$ fluorescence, and gelbstoff absorption at $350 \mathrm{~nm}$, for station 7, 24th May 97, 16 $\left.\left.12.23^{\prime} \mathrm{N}, 60^{\circ} 19.6^{\prime} \mathrm{E}, \mathbf{a}\right), \mathbf{b}\right)$ and c) respectively. In situ fluorescence profiles are normalized to the Raman signal. Thin lines are in situ data in relative units.
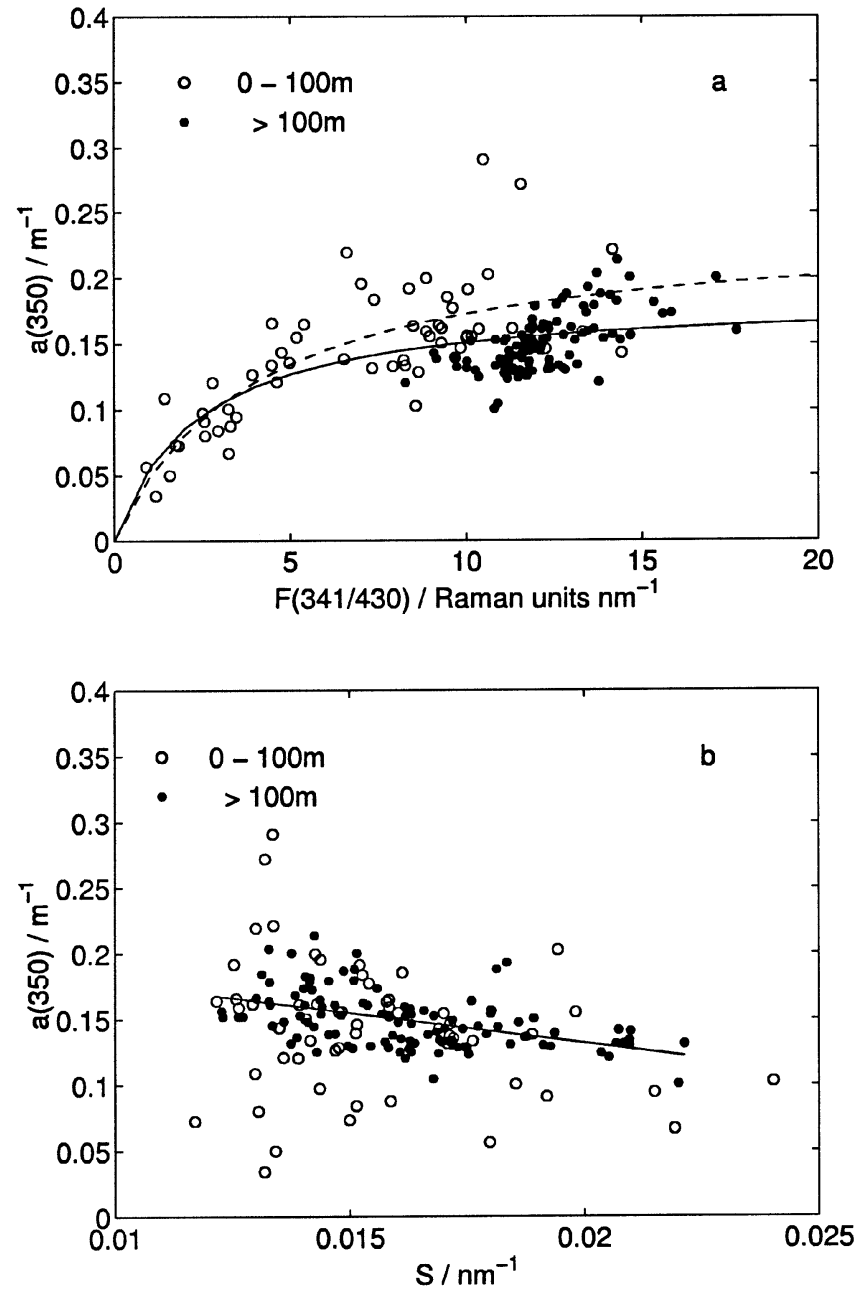

Figure 5. Absorption vs. fluorescence data. a) gelbstoff fluorescence vs. gelbstoff absorption at $350 \mathrm{~nm}$. The solid line represents the fit on a basis of all data $\left(\nu=0.19 \mathrm{~m}^{-1}, k=2.33\right.$ Raman units $\left.\mathrm{nm}^{-1}\right)$, the dashed line the fit taking into account data from the upper $100 \mathrm{~m}$ only data $\left(\nu=0.24 \mathrm{~m}^{-1}\right.$, $k=3.96$ Raman units $\mathrm{nm}^{-1}$ ). For further explanation see text. b) Gelbstoff absorption coefficient at $350 \mathrm{~nm}$ vs. slope parameter $S$.

between absorption coefficient and slope $S$ for data of aphotic depth, while data from the euphotic zone is scattered. Any effects of $\mathrm{pH}$ changes on absorption coefficients and fluorescence as reported by Ferrari (1991) and Ferrari and Tassan (1991) were neglected in this diagram. These effects seem to be of minor importance in this context because regions of strong gradients as in estuaries were not sampled during So119. Obviously absorption coefficients do not depend linearly on fluorescence. The relation is rather mathematically described by a Michaelis Menten saturation curve

$$
a_{g}(350)=\nu \frac{F(341 / 430)}{k+F(341 / 430)}
$$

$\nu$ and $k$ were obtained from a least square fit, taking on values of $0.19 \mathrm{~m}^{-1}$ and 2.33 Raman units $\mathrm{nm}^{-1}$, 
respectively. In theory this behaviour might be due to two different molecular pools, where one is stable regarding absorption but variable in fluorescence, while the other shows a proportional change in its absorption and fluorescence properties.

A linear relationship of gelbstoff absorption versus fluorescence has been reported (Hoge et al 1993; Green and Blough 1994; Nieke et al 1997). However, the reported dependencies differ depending on the excitation and emission wavelength considered as well as the data processing procedures such as background corrections, normalisation, integrated or peak values, and the area under study. Ferrari and Tassan (1991) reported a linear relationship of $a_{g}(375)=(0.052 \pm$ $0.055)+(0.973 \pm 0.045) F$ over an $a_{g}(375)$ range of 0 and $5 \mathrm{~m}^{-1}$. Fluorescence $F$ was measured as peak height (ex308/em420) after correction for water background and normalisation to the intensity of the Raman peak of a distilled water sample. Absorption was obtained by least-square fit in the range of 300 to $450 \mathrm{~nm}$ and a spectral slope $S=0.014 \mathrm{~nm}^{-1}$.

The reported linear correlations do not hold in regions of low gelbstoff levels such as the open ocean, which probably explains the differences from our data. These deviations may result from the variability of the quantum efficiency due to the actual chromophores and the photochemical history of the gelbstoff. Observed changes in the exponential slope $S$ may be due to changes in the relative fractions of fulvic to humic acids (Carder et al. 1989), photodegradation in the near-surface layer, in situ production and biological activity (Coble and Brophy 1994).

In the context of new production estimates on ocean-basin scales, the association of our stations to biogeographical provinces due to the gelbstoff absorption is of interest. Following the bio-hydro-optical classification of Brock et al (1998) for the northwestern Indian Ocean, the region under study principally falls within the typical tropical class at the onset of the southwest monsoon. Watts et al (1999) define biogeographic provinces based on the bathymetry, the sea-surface temperature and chlorophyll measurements. Assuming, that their findings are transferable, stations fall within different classes and do not always fulfill all criteria. Stations 6, 7, 19, 20 and 21 should fall within the 'OCNS' province (see figure 1), that is, waterdepth of more than $3975 \mathrm{~m}$, SST greater equal $27^{\circ} \mathrm{C}$, and sea-surface chlorophyll concentrations of less than $0.3 \mathrm{mg} \mathrm{m}^{-3}$. However, the data for the classification is incomplete concerning chlorophyll concentrations, and information on gelbstoff absorption at these stations is sparse as well. Most stations were deeper than $2500 \mathrm{~m}$ with low to intermediate sea surface chlorophyll concentrations, but SST was higher than $27^{\circ} \mathrm{C}$. Thus, stations do not fall within the 'OCNN' province. The existing absorption data cannot be attached to the described provinces on this basis.

\subsection{Contribution of fluorescence data to the interpretation of biogeochemical dynamics}

Fluorescence measurements are often used for studying phytoplankton and gelbstoff because methodical efforts are low and in situ measurements are straightforward. On the other hand, varying and mostly unknown quantum efficiencies may lead to unpredictable variations in the fluorescence readings, especially if chlorophyll fluorescence is considered. Nevertheless, a comparison of chlorophyll $a$ fluorescence and extracted chlorophyll $a$ measured during So119 reveals an approximately linear relation, whereas gelbstoff and DOC do not correlate (Breves et al unpubl.). Thus, chlorophyll $a$ fluorescence can be used as an estimate for the chlorophyll $a$ concentration, while the fluorescence intensity of gelbstoff cannot be derived from the DOC concentration or vice versa.

Fluorescence data of station 7 are shown in figure 6 , where the chlorophyll $a$ peak coincides with slight local maxima of tryptophan-like and gelbstoff fluorescence. Like gelbstoff fluorescence, chlorophyll $a$ fluorescence is compared to the gelbstoff absorption coefficient at $350 \mathrm{~nm}$ and the slope parameter $S$ at all stations (figure 7 ), revealing no correlation.

In the region off the Omani coast the evolution of filaments was observed as a result of strong upwelling during the southwest monsoon. Their structure can be easily seen on sea surface temperature (SST) satellite data. During the So119 cruise a filament was sampled on stations 37 and 41. An analysis of satellite data led us to assume that we sampled the same water body at both stations. At station 37 (figure 8) the surface temperature is $2^{\circ} \mathrm{C}$ lowered and a pronounced chlorophyll fluorescence maximum is visible at 20 to $30 \mathrm{~m}$
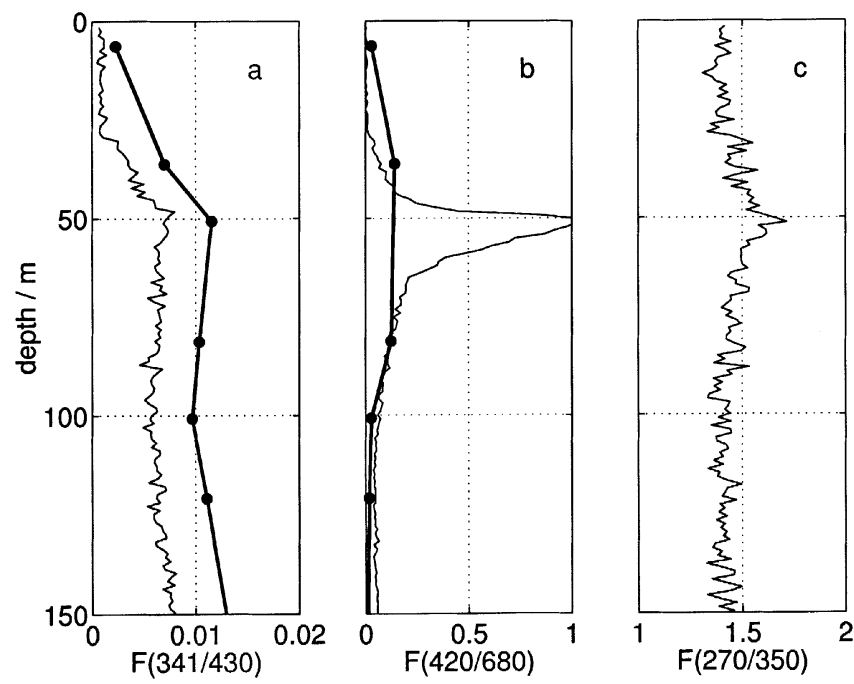

Figure 6. Vertical profiles of gelbstoff, chlorophyll $a$ and tryptophan-like fluorescence for station 7, 24th May 97, $\left.\left.16^{\circ} 12.23^{\prime} \mathrm{N}, 60^{\circ} 19.6^{\prime} \mathrm{E}, \mathbf{a}\right), \mathbf{b}\right)$ and $\left.\mathbf{c}\right)$, respectively. In situ fluorescence profiles are normalized to the Raman signal. Thin lines are in situ data in relative units. 

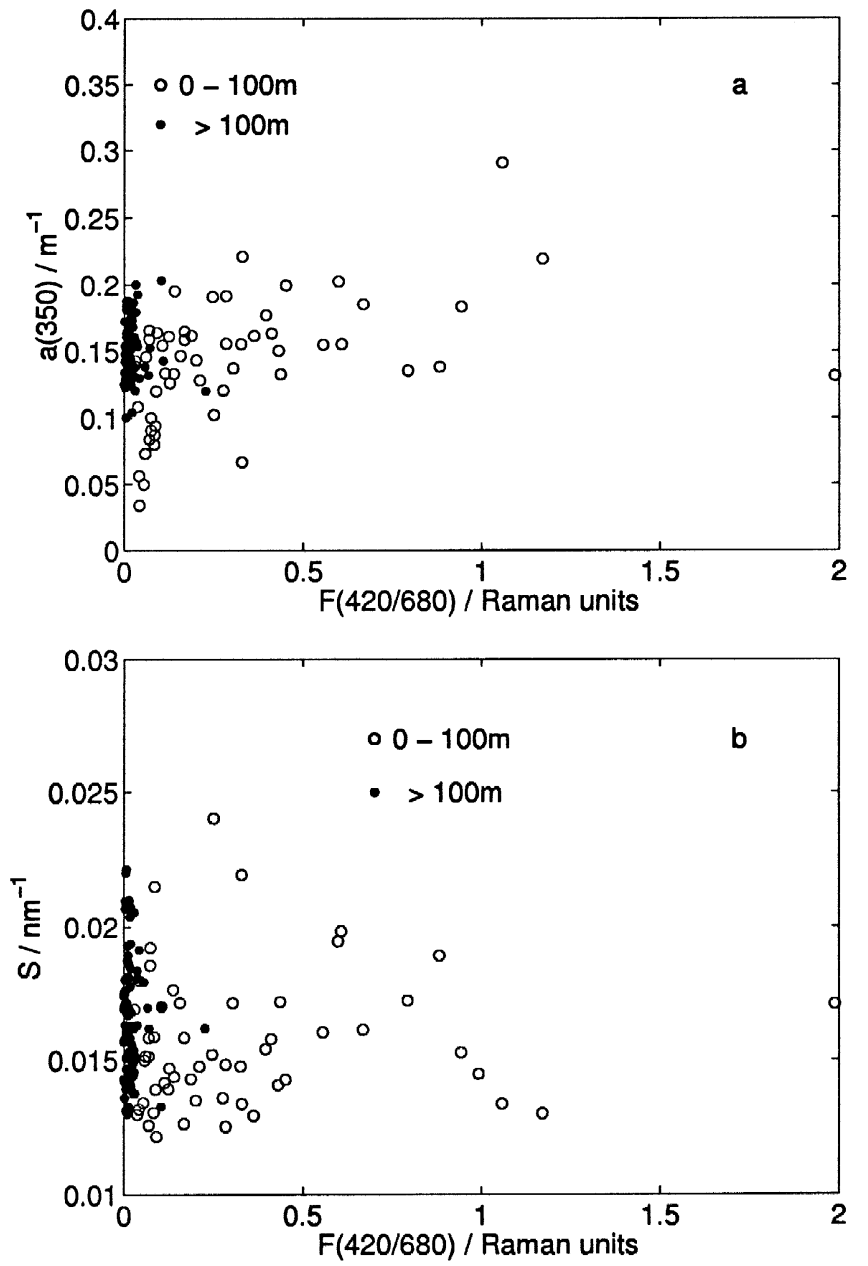

Figure 7. a) Chlorophyll $a$ fluorescence vs. gelbstoff absorption at $350 \mathrm{~nm}$ and b) Chlorophyll $a$ fluorescence vs. slope parameter $S$.

depth. Upon sampling at the same site about 40 hours later (station 40) these characteristics could not be observed again since the water had propagated to the northeast. Only at station 41 the 'same' water mass was sampled, although already altered. Chlorophyll signals are less pronounced but tryptophan-like signals are enhanced. The discussed tryptophan-like signal is due to the combined effect of algae and bacteria activities in the photic zone. We suppose that proteinlike fluorescence might be related to more recent exudates (Mopper and Schultz 1993; Coble et al 1998; Determann et al 1998).

Upwelled water is known to be rich in nutrients and the better nutrient availability allows for enhanced phytoplankton growth. As a consequence, a second, clearly visible pigment fluorescence signal can also be seen less deep than the usual chlorophyll maximum (figure 8 top). Inside a filament, the physical parameters temperature and salinity remain preserved in the beginning. However, the nutrient supply, which is at first maintained through the upwelling process, is interrupted as the filament moves on. The phyto- plankton becomes nutrient limited and eventually dies. Exudates and degradation products of the algae may lead to an increased signal in the gelbstoff fluorescence signal. In figure 9, the chlorophyll to tryptophan-like fluorescence ratios for station 37 and 41 are shown. On the basis of these data the following hypothesis is suggested. The increased tryptophan-like fluorescence at an unchanged or lowered chlorophyll fluorescence level, e.g., the lower chl/trp ratio, may be indicative of bacterial biomass or 'age of the bloom'. Dortch and Packard (1989) examined the differences in biomass structure between oligotrophic and eutrophic marine ecosystems. To differentiate between plant and non-plant biomass the chlorophyll $a$ to protein ratio of particulate matter has been used as a relative index of phytoplankton to total biomass. Oligotrophic areas revealed a low ratio, indicating that bacteria and zooplankton comprise a large part of the biomass, while the high ratio in eutrophic areas suggested the dominance of phytoplankton. They used data collected over 13 years with a variety of methods. These results can be compared with the So119 data only to a certain extent, since we measured total tryptophan-like fluorescence of the water instead of particulate protein. However, the basic hypothesis, that is, high ratios are due to phytoplankton biomass and low ratios due to relatively more bacteria and zooplankton, still holds. Species compositions and environmental effects such as temperature, nitrogen or light availability that may lead to changed ratios of chlorophyll to protein could not be considered (see discussion in Dortch and Packard 1989).

Determann et al. (1998) compared the intensity of the emission band at $340 \mathrm{~nm}($ ex230) with cell number and protein content. They found the same fluorescence signature with standard proteins of known composition, which was due to its tryptophan and tyrosine content. Thus, the UV fluorescence of marine particles can be related to these two amino acids. Linear relations between fluorescence intensity and bacterial and algal biomass were deduced. In the dissolved state tryptophan metabolites such as tryptamine, serotonon and dimethyl tryptamine, which emit at 340-360 nm with an efficiency comparable to tryptophan when excited at $270 \mathrm{~nm}$ wavelength (Wolfbeis 1985), may also play a role. Thus, in natural waters the signals probably reflect a mixture of tryptophan and its metabolites.

\section{Conclusions}

As long as the gelbstoff concentration varies over a broad range, relationships of absorption versus fluorescence are easier to calculate and to validate. In oceanic waters typically only a small range of concentrations exist, leading to uncertainties or even a lack of correlation. The absorption coefficients found 

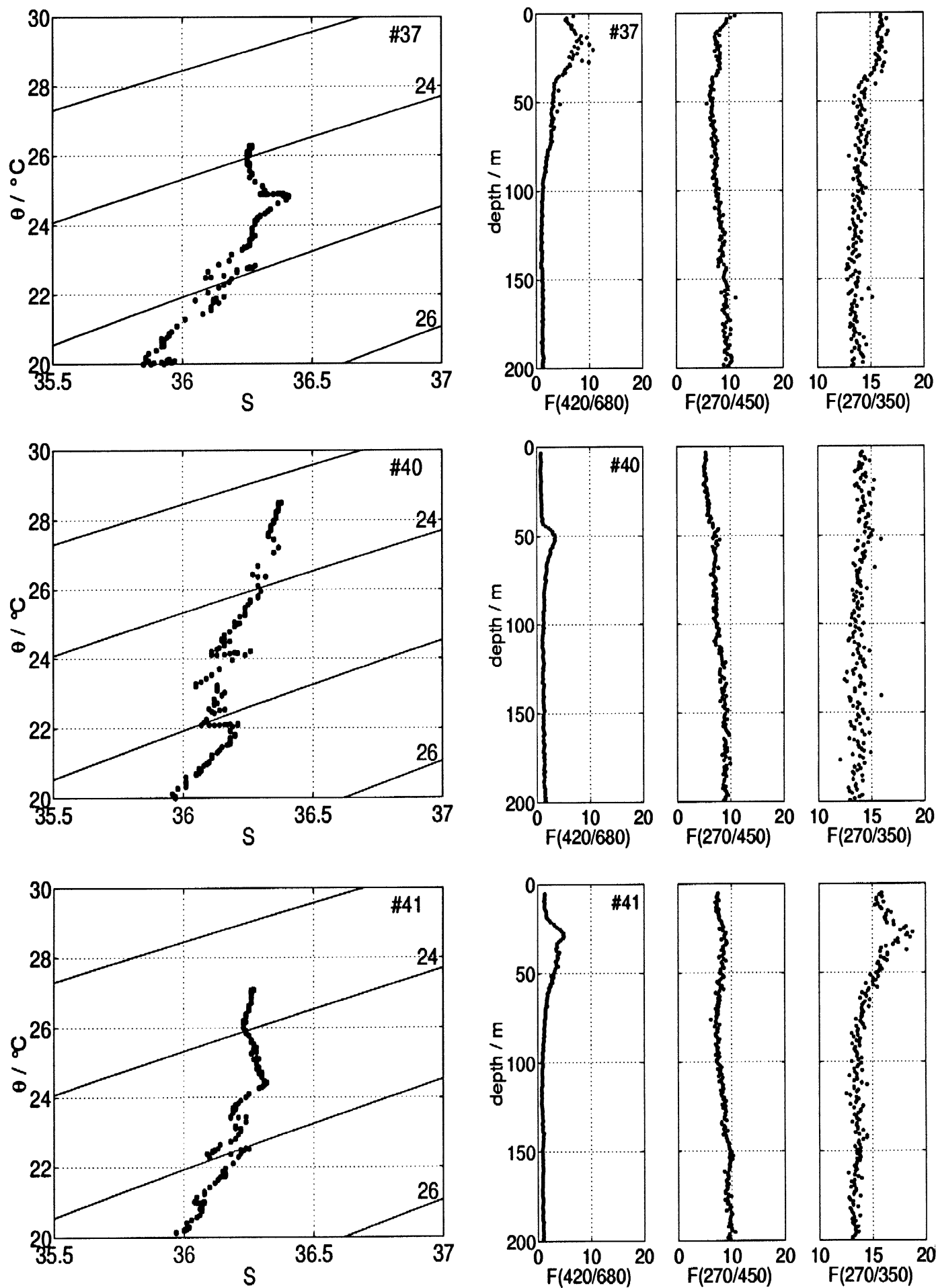

Figure 8. $\theta \mathrm{S}$ diagrams (left) and in situ fluorescence profiles (right) at station 37, 40 and 41, from top to bottom. In situ fluorescence profiles are normalized to the Raman signal. Station 37: 3rd June 97, $20^{\circ} 33.96$ 'N, 60 03.15'E; station 40: 4th June 97, $20^{\circ} 33.99^{\prime} \mathrm{N}, 60^{\circ} 03.16^{\prime} \mathrm{E}$ and station 41 : 5th June $97,20^{\circ} 41.07^{\prime} \mathrm{N}, 60^{\circ} 23.04^{\prime} \mathrm{E}$.

during So119 lie within the typical range for oceanic waters. They are relatively weak, and calculated $S$ values are slightly higher than the previously reported values, taking on a mean of $0.016 \mathrm{~nm}^{-1}$. The relation between gelbstoff absorption coefficients and fluorescence readings is rather of a Michaelis Menten type than linear. Altogether some of the analysed absorption spectra differ from the typical exponential appearance due to an additional absorption band, underlining the importance of a suitable fit procedure. An assumed fixed mean slope of $S=0.014 \mathrm{~nm}^{-1}$ might lead to a systematic over- or underestimation when 


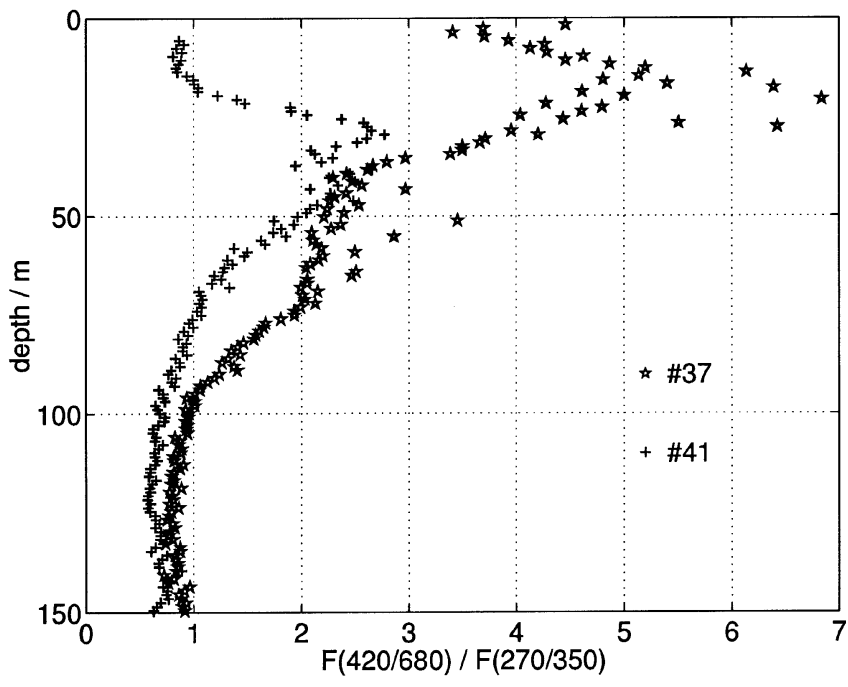

Figure 9. Depth profiles of the chlorophyll $a$ to tryptophan-like fluorescence ratio at stations 37 and 41, e.g. in the filament.

extrapolating absorption data taken at a single wavelength to other spectral regions.

A slight linear trend of decreasing $a_{g}(350)$ values with increasing $S$ values is evident in data from aphotic depth, while data from the euphotic zone is scattered. A functional relation of this kind for the euphotic zone would be of interest if absorption coefficients are extrapolated into the visible. However, it could be a starting point for further studies to reveal whether there is a significant relation and whether $\mathrm{S}$ should be expressed as a function of $a_{q}\left(\lambda_{0}\right)$ rather than as a mean, when used for extrapolation into the visible.

Regarding remote sensing, surface data of gelbstoff absorption are of special interest. Unfortunately, surface data are sparse and no clear geographical dependency could be deduced. Values of the absorption coefficient at $375 \mathrm{~nm}$ in the upper $10 \mathrm{~m}$ of the water column range from $0.02 \mathrm{~m}^{-1}$ to $0.15 \mathrm{~m}^{-1}(0.33$ $\mathrm{m}^{-1}$ at one station close to the Omani coast) with a median of $0.04 \mathrm{~m}^{-1}$. They fall within the range of 0.022 to $0.288 \mathrm{~m}^{-1}$ for surface waters of the west Arabian Sea (Coble et al 1998). Carder et al (1989) stated that a $440 \mathrm{~nm}$ gelbstoff absorption coefficient of about $0.005 \mathrm{~m}^{-1}$ is already equivalent to the phytoplankton absorption at a chlorophyll $a$ level of $0.10 \mathrm{mg} \mathrm{m}^{-3}$. Since the presented values of $a_{g}(440)$ are all well above this value, they may influence the ocean colour and affect remote sensing.

Although still under discussion, the extended use of tryptophan-like signals in oceanography may provide further insight into biogeochemical dynamics, supporting hydrographic, bacteria, chlorophyll $a$ and nutrient data. The given interpretation is still preliminary and further analysis of tryptophan-like fluorescence is necessary to prove the suitability of an advanced use of fluorescence data.

\section{Acknowledgements}

This work was supported by a grant from the Federal Minister of Education and Technology, Bonn, within the frame of the JGOFS Arabian Sea programme. We are grateful to the captain and the crew of RV Sonne for their support. Special thanks are due to the chief scientist of the cruise, Pr. V. Ittekkot, for helpful discussions.

SST image provided by Rosenstiel School of Marine \& Atmospheric Sciences, University of Miami, http:// www.rsmas.miami.edu/images.html.

\section{References}

Baek M, Nelson W H, Hargraves P E, Tanguay J F and Suib S L 1988 The steady-state and decay characteristics of protein tryptophan fluorescence from algae; Applied Spectroscopy 42 1405-1412

Barth H, Heuermann R, Loquay K D, Reuter R and Stute U 1997 Long-term stable sensors for bio-optical measurements. In: Operational Oceanography, (eds) J H Stel, H W A Behrens, J C Borst, L J Droppert and J P van der Meulen (Amsterdam: Elsevier Oceanography Series) pp. 133-140

Breves W, Heuermann $\mathrm{R}$ and Reuter $\mathrm{R}$ Enhanced red fluorescence emission in the oxygen minimum zone of the Arabian Sea; Deep-Sea Res. (submitted.)

Breves W, Reuter R, Delling N und Michaelis W Fluorophores in the Arabian Sea and their relation to upwelling processes; Deep-Sea Res. (submitted.)

Bricaud A, Morel A and Prieur L 1981 Absorption by dissolved organic matter (yellow substance) in the UV and visible domains; Limnology and Oceanography 26 43-53

Brock J C, Sathyendranath S, Platt T 1998 Biohydro-optical classification of the northwestern Indian Ocean; Marine Ecology Progress Series 165 1-15

Carder K L, Steward R G, Harvey G R and Ortner P B 1989 Marine humic and fulvic acids: Their effects on remote sensing of ocean chlorophyll; Limnology and Oceanography 34 68-81

Chen R F and Bada J L 1992 The fluorescence of dissolved organic matter in seawater; Marine Chemistry 37 191-221

Coble P G 1996 Characterization of marine and terrestrial DOM in seawater using excitation-emission matrix spectroscopy; Marine Chemistry 51 325-346

Coble P G and Brophy M M 1994 Investigation of the geochemistry of dissolved organic matter in coastal waters using optical properties. SPIE Vol.2258, Ocean Optics XII, 377-391

Coble P G, Del Castillo C E and Avril B 1998 Distribution and optical properties of CDOM in the Arabian Sea during the 1995 Southwest Monsoon; Deep-Sea Res. Part II, 45 2195-2223

Daltiero R A, Nelson W H, Britt D, Sperry J, Psaras D, Tanguay J F and Suib S L 1986 Steady-state and decay characteristics of protein tryptophan fluorescence from bacteria; Applied Spectroscopy 40 86-90

De Souza Sierra M M and Donard O F X 1991 Simulation of fluorescence variability in estuaries; Oceanologica Acta $\mathbf{1 1}$ $275-284$

De Souza Sierra M M, Donard O F X, Lamotte M, Belin C, Ewald M 1994 Fluorescence spectroscopy of coastal and marine waters; Marine Chemistry, 47, 127-144

Determann S 1995 Analyse biologischer und biogeochemischer Prozesse im Meer mit Fluoreszenzspektroskopie. Doktorarbeit, Carl von Ossietzky University Oldenburg 
Determann S, Reuter R, Wagner P and Willkomm R 1994 Fluorescent matter in the eastern Atlantic Ocean. Part 1: Method of measurement and near-surface distribution; Deep-Sea Res. 41 659-675

Determann S, Lobbes J M, Reuter R and Rullkötter J 1998 UV fluorescence excitation and emission spectroscopy of marine algae and bacteria; Marine Chemistry 62 137-156

Dortsch Q and Packard T T 1989 Differences in biomass structure between oligotrophic and eutrophic marine ecosystems; Deep-Sea Res. 36 223-240

Ewald M, Stabel H H, Belin C 1986 Composés organiques d'origine biogénique en Antarctique étudiés directement pasr spectrofluorimétrie. Contes Rwendues de l'Académie des Sciences Paris, 302, 883-886

Ferrari G M 1991 Influence of $\mathrm{pH}$ and heavy metals in the determination of yellow substance in estuarine areas; Remote Sens. Environment 89-100

Ferrari G M and Tassan S 1991 On the accuracy of determining light absorption by 'yellow substance' through measurements of induced fluorescence; Limnology and Oceanography 36 777-786

Green S A and Blough N V 1994 Optical absorption and fluorescence properties of chromophoric dissolved organic matter in natural waters; Limnology and Oceanography 39 1903-1916

Heuermann R, Loquay K D and Reuter R 1995 A multiwavelength in situ fluorometer for Hydrographic Measurements. EARSeL Advances in Remote Sensing 3 71-77

Hoge F E, Vodacek A and Blough N V 1993 Inherent optical properties of the ocean: retrieval of the absorption coefficient of chromophoric dissolved organic matter from fluorescence measurements; Limnology and Oceanography 38 1394-1402

Højerslev N K 1988 Natural occurrences and optical effects of gelbstoff. (Copenhagen: Geophysical Institute, Dept. of Physical Oceanography.)

Jerlov N G 1976 Marine Optics. Elsevier Sci. Publ. Amsterdam, 231pp.

Kalle K 1963 Über das Verhalten und die Herkunft der in den Gewässern und in der Atmosphäre vorhandenen himmelblauen Fluoreszenz. Deutsche Hydrographische Zeitung, 16 153-166.
Kirk J T O 1994 Light and Photosynthesis in aquatic ecosystems (Cambridge University Press) 2nd ed.

Lorenzen C J 1966 A method for the continuous measurement of in vivo chlorophyll concentration. Deep-Sea Res 13 $223-227$

Mopper K and Schultz C A 1993 Fluorescence as a possible tool for studying the nature and water column distribution of DOC components; Marine Chemistry 41 229-238

Nieke B, Reuter R, Heuermann R, Wang H, Babin M and Therriault J C 1997 Light absorption and fluorescence properties of chromophoric dissolved organic matter (CDOM), in the St. Lawrence Estuary (case 2 waters); Continental Shelf Research 17 235-252

Spitzy A and Ittekkot V 1986 Gelbstoff: an uncharacterized fraction of dissolved organic carbon. In: The influence of yellow substance on remote-sensing of seawater-constituents from space, 2, GKSS Geesthacht Research Center, Geesthacht, Germany, 1-31

Traganza E D 1969 Fluorescence excitation and emission spectra of dissolved organic matter in sea water; Bulletin of Marine Sciences 19 897-904

Velapoldi R A and Mielenz K D 1980 A fluorescence standard reference material: quinine sulfate dihydrate: NBS Special Publication SP 260-64. National Bureau of Standards, Washington DC, 139pp.

Watts L J, Sathyendranath S, Caverhill C, Maass H, Platt T and Owens N J P 1999 Modelling new production in the northwest Indian Ocean region; Marine Ecology Progress Series, 183 1-12

Wolfbeis O S 1985 Fluorescence of organic natural products. In. Chemical Analysis, P J Elving, and J P Winefordner (eds) 77 167-370 (John Wiley \& Sons)

Yentsch C S and Menzel D W 1963 A method for the determination of phytoplankton chlorophyll and phaeophytin by fluorescence; Deep-Sea Res 10 221-231

Zepp R G and Schlotzhauer F 1981 Comparison of photochemical behaviour of various humic substances in water: III spectroscopic properties of humic substances; Chemosphere 10(5) 479-486 